\title{
Health anxiety in Australia: prevalence, comorbidity, disability and service use ${ }^{\dagger}$
}

Matthew Sunderland, Jill M. Newby and Gavin Andrews

\section{Background}

Health anxiety is associated with high distress, disability and increased health service utilisation. However, there are relatively few epidemiological studies examining the extent of health anxiety or the associated sociodemographic and health risk factors in the general population.

\section{Aims}

To provide epidemiological data on health anxiety in the Australian population.

\section{Method}

Lifetime and current prevalence estimates, associations between comorbid disorders, psychological distress, impairment, disability and mental health service utilisation were generated using the Australian 2007 National Survey of Mental Health and Wellbeing.

\section{Results}

Health anxiety affects approximately $5.7 \%$ of the Australian population across the lifespan and $3.4 \%$ met criteria for health anxiety at the time of the interview. Age, employment status, smoking status and comorbid physical conditions were significantly related to health anxiety symptoms. Health anxiety was associated with significantly more distress, impairment, disability and health service utilisation than that found in respondents without health anxiety.

\section{Conclusions}

Health anxiety is non-trivial; it affects a significant proportion of the population and further research and clinical investigation of health anxiety is required.

\section{Declaration of interest}

None.

of $60 \%$. The survey was conducted between August and December of 2007 and administered by trained lay-interviewers from the Australian Bureau of Statistics (ABS). The survey generated representative estimates of non-institutionalised Australian private households (excluding remote or sparsely populated areas) utilising a stratified, multistage area sampling design. These data were weighted for the gender and age distribution of the Australian population and the younger (16-24) and older (65-85) age groups were oversampled (higher probability of being selected for the interview) to ensure reliable estimates among these underrepresented age groups. The sample characteristics of the 2007 survey have been described in detail previously. ${ }^{12}$ Briefly, the ratio of male to female was approximately equal and $33.5 \%$ were aged between 16 and 34, 37\% were aged between 35 and 54, and 29.5\% were aged 55 and over. The majority of the population were married, employed, possessed no higher education qualification costs alone, that hypochondriasis and the related concept of severe health anxiety must be taken seriously, and diagnosed and treated as a routine. Despite the apparent seriousness and large economic cost of health anxiety, there are relatively few epidemiological studies examining the extent of the symptoms or the associated sociodemographic and health risk factors in the general population. ${ }^{9}$ The lack of evidence on health anxiety limits the greater understanding of this condition in the population and restricts the ability for health policy makers to properly plan and fund treatment and prevention services to reduce the overall disease burden. ${ }^{10,11}$ The current study aims to address the paucity of epidemiological data on health anxiety in Australia by investigating data from the 2007 National Survey of Mental Health and Wellbeing (NSMHWB).

\section{Method}

\section{Sample}

The sample comprised 8841 respondents aged between 16 and 85 from the Australian 2007 NSMHWB, representing a response rate

Tee editorial, pp. 7-8, this issue. and were born in Australia.

\section{Assessment}

The core diagnostic assessment was conducted using the World Mental Health version of the Composite International Diagnostic Interview (WMH-CIDI), ${ }^{13}$ a comprehensive lay intervieweradministered structured diagnostic interview. In addition to the assessment of common mental disorders, the 2007 survey contained brief questions to assess the possible presence of health anxiety (see Appendix for assessment items). The questions were not designed to directly assess each DSM-IV criterion required for a diagnosis of hypochondriasis. However, they were designed to match the diagnostic construct of severe and persistent anxiety about serious illness or health problems despite professional reassurance. Lifetime information on health anxiety was collected by enquiring about whether the respondent ever worried a lot about serious illness, despite having reassurance from a doctor or medical specialist. If endorsed, the respondents were asked whether they ever had a period of worry like this that lasted for 6 months or longer. They were then asked if they have 
experienced a period of worry in the previous 12 months and if they were currently experiencing a period of worry about serious illness. For the current study, if the respondent indicated that they experienced a period of worry and that it lasted for at least 6 months, they were defined as having a history of health anxiety. Criteria for current health anxiety were met if the respondent indicated that they were currently experiencing persistent worry about serious illness/health at the time of the interview. (The nature of the design and administration of the 2007 NSMHWB prevented the lay interviewers from making a DSM-IV diagnosis of hypochondriasis, as they were unable to assess differential diagnoses. That is, they were unable to assess whether the illness worries were better accounted for by other disorders such as generalised anxiety disorder (Criterion F, DSM-IV) and whether the beliefs were of delusional intensity (Criterion C, DSM-IV).)

Additional psychiatric diagnoses were made by systematically addressing each DSM-IV criterion for the particular disorder under examination. The disorders that were assessed in the 2007 survey included: major depression, dysthymia, bipolar disorder, agoraphobia, panic disorder, social phobia, generalised anxiety disorder, obsessive-compulsive disorder (OCD) and post-traumatic stress disorder (PTSD). The hierarchical exclusion criteria were applied for a diagnosis of major depression, dysthymia and generalised anxiety disorder. The criteria were assessed using a lifetime time frame, meaning that all questions were prefaced using 'have you ever...' or 'in your lifetime ...' and a 12-month or 30-day point prevalence estimate was made by determining whether the symptoms endorsed over the respondent's lifetime were present in the previous 12 months or in the previous 30 days. The diagnostic validity of the WMH-CIDI modules has been examined previously using clinical reappraisal studies, which found that the WMH-CIDI exhibited satisfactory validity when compared with diagnoses made using a semi-structured clinical interview. ${ }^{14}$ In addition to the individual diagnoses, aggregate diagnoses were also estimated by combining major depression, dysthymia and bipolar disorder to form the diagnosis of any affective disorder, whereas agoraphobia, panic disorder, social phobia, generalised anxiety disorder, OCD and PTSD were combined to form the diagnosis of any anxiety disorder. Finally, the aggregate diagnosis of depression and anxiety was formed by combining depression (major depressive disorder only) and/or any anxiety disorder.

The 2007 NSMHWB also contained additional screening questions/questionnaires for physical disorders, psychological distress, functional impairment, days out of role and mental health service utilisation. Physical disorders assessed included: asthma, cancer, stroke, gout, rheumatism, arthritis, diabetes, heart or circulatory condition, hay fever, sinusitis, emphysema, bronchitis, anaemia, epilepsy, oedema, hernias, kidney problems, migraine, psoriasis, stomach ulcer, thyroid trouble, tuberculosis and back or neck problems. Psychological distress was measured using the 10-item Kessler Psychological Distress Scale (K10). ${ }^{15}$ This questionnaire measures non-specific psychological distress in the previous 30 days with scores that can range from 10 to 50, higher scores indicating higher distress. The K10 has previously exhibited excellent psychometric properties and significant associations with DSM-IV anxiety and affective disorders. ${ }^{16-19}$

Functional impairment or activity limitation was measured using the 12-item World Health Organization Disability Assessment Schedule (WHODAS). The WHODAS measures activity limitation that could be associated with physical illness, mental illness or a combination of both, whereas the K10 measures distress primarily related to mental illnesses such as depression and anxiety. The WHODAS ranges from 1 to 100, with higher scores indicating higher functional impairment/activity limitation. Studies have previously indicated that the WHODAS possesses excellent psychometric properties. ${ }^{20}$ Days out of role was measured by asking people to nominate the total number of days in the previous 30 that they were unable to work or carry out their normal activities because of their health. Finally, mental health service utilisation was measured by asking respondents to indicate whether they sought help for a mental health problem in the previous 12 months from their general practitioner (GP) and/or a mental health specialist.

\section{Analysis}

Estimates for the total population and stratified by age and gender were calculated for both lifetime and current point prevalence of health anxiety. Multivariate logistic regression was used to assess the sociodemographic and health risk factors associated with health anxiety. The frequency of individual comorbid conditions was calculated for those with and those without health anxiety. Lifetime comorbid conditions were matched to the lifetime presence of health anxiety and 30-day comorbid conditions were matched to the current presence of health anxiety. Univariate logistic regression was used to estimate the odds of having a comorbid condition given that a respondent had health anxiety compared with a respondent who did not. The mean number of comorbid conditions was estimated and compared between those with and without health anxiety using Poisson regression, as suggested for the analysis of highly skewed count data. Finally, mean levels of distress, impairment, days out of role and health service utilisation were compared between those with and those without health anxiety using Poisson regression and $\chi^{2}$ analysis. To account for the bias associated with the complex sampling design, all point estimates were weighted and variance estimates were adjusted using a balanced repeated replication technique. ${ }^{21}$ The SUDAAN statistical software package for Windows was used for all analyses. ${ }^{22}$

\section{Results}

\section{Prevalence}

Of the total Australian sample studied, 5.7\% (s.e. =0.31) have met criteria for health anxiety at some point in their life, as determined by the screening questions. A total of $4.2 \% \quad($ s.e. $=0.24)$ experienced health anxiety in the past 12 months and $3.4 \%$ $($ s.e. $=0.25)$ were currently experiencing health anxiety at the time of the survey. Approximately $60 \%$ of people who experienced health anxiety at some point in their life currently had health anxiety at the time of the survey. The lifetime and current point prevalence estimates for health anxiety stratified by age and gender are presented in Table 1 and Table 2 respectively. The prevalence of health anxiety appears to peak in middle age at $7.4 \%$ before declining by approximately a half in old age. Female respondents had, on average, slightly higher albeit non-significant lifetime and current prevalence estimates in comparison with male respondents.

\section{Sociodemographic and health risk factors}

The multivariate logistic regressions examining sociodemographic and health risk factors for lifetime and current health anxiety are presented in Table 3. Age was a significant predictor in the model for both lifetime and current prevalence; however, the individual pair-wise comparisons of the age bands (using 16-24 as the reference) resulted in no significant differences, as demonstrated by the inclusion of 1.00 in the $95 \%$ confidence intervals around the odds ratios. There were few other significant 
Table 1 Lifetime prevalence estimates of health anxiety by age and gender in the Australian population

\begin{tabular}{|lccc|} 
& \multicolumn{3}{c}{$\%($ s.e. } \\
\cline { 2 - 4 } Age, years & Male & Female & Total \\
\hline $16-24$ & $1.84(0.60)$ & $5.73(1.20)$ & $3.75(0.67)$ \\
\hline $25-34$ & $3.41(0.87)$ & $6.23(1.00)$ & $4.81(0.66)$ \\
\hline $35-44$ & $7.83(1.55)$ & $7.04(1.26)$ & $7.43(0.97)$ \\
\hline $45-54$ & $6.54(1.50)$ & $7.96(1.67)$ & $7.26(1.20)$ \\
\hline $55-64$ & $5.89(0.99)$ & $7.21(1.17)$ & $6.55(0.76)$ \\
\hline $64-85$ & $3.39(0.85)$ & $4.62(0.72)$ & $4.04(0.52)$ \\
\hline Total & $4.92(0.45)$ & $6.51(0.50)$ & $5.72(0.31)$ \\
\hline
\end{tabular}

sociodemographic predictors of lifetime and current health anxiety except for employment status, with those not in the labour force having a greater probability of experiencing health anxiety in comparison with those currently employed. Of the health factors, comorbid physical conditions and smoking status were strong predictors of health anxiety. As demonstrated in Table 3, respondents who experience at least one physical illness were 4.67 times more likely to meet criteria for current health anxiety in comparison with respondents who were relatively healthy.
Table 2 Current prevalence estimates of health anxiety by age and gender in the Australian population

\begin{tabular}{|lccc|}
\hline & \multicolumn{3}{c}{$\%($ s.e. } \\
\cline { 2 - 4 } Age, years & Male & Female & Total \\
\hline $16-24$ & $1.29(0.56)$ & $2.52(0.65)$ & $1.89(0.41)$ \\
\hline $25-34$ & $2.00(0.63)$ & $4.15(0.90)$ & $3.07(0.50)$ \\
\hline $35-44$ & $4.60(1.16)$ & $4.26(0.95)$ & $4.43(0.68)$ \\
\hline $45-54$ & $3.71(1.07)$ & $5.02(1.29)$ & $4.37(0.84)$ \\
\hline $55-64$ & $3.38(0.79)$ & $4.31(0.92)$ & $3.84(0.60)$ \\
\hline $64-85$ & $2.56(0.75)$ & $2.91(0.62)$ & $2.75(0.46)$ \\
\hline Total & $2.97(0.35)$ & $3.91(0.43)$ & $3.44(0.25)$ \\
\hline
\end{tabular}

\section{Comorbidity, distress, impairment}

\section{and health service use}

The associations between health anxiety and other comorbid mental health conditions are presented in Table 4. The univariate logistic regressions indicated that respondents with health anxiety were significantly more likely to experience any comorbid condition in comparison with respondents without health anxiety. Indeed, bipolar disorder, agoraphobia, panic disorder and generalised anxiety disorder were some of the more likely

\begin{tabular}{|c|c|c|c|c|c|c|c|c|}
\hline \multirow[b]{2}{*}{ Variable } & \multicolumn{4}{|c|}{ Lifetime prevalence } & \multicolumn{4}{|c|}{ Current prevalence } \\
\hline & OR & $95 \% \mathrm{Cl}$ & Wald $F$ & $P$ & OR & $95 \% \mathrm{Cl}$ & Wald $F$ & $P$ \\
\hline Age, years & & & 27.55 & $<0.001$ & & & 21.27 & 0.001 \\
\hline $16-24$ & 1.00 & - & & & 1.00 & - & & \\
\hline $25-34$ & 1.07 & $0.66-1.76$ & & & 1.28 & $0.70-2.36$ & & \\
\hline $35-44$ & 1.54 & $0.84-2.82$ & & & 1.51 & $0.80-2.86$ & & \\
\hline $45-54$ & 1.49 & $0.83-2.69$ & & & 1.48 & $0.79-2.75$ & & \\
\hline $55-64$ & 1.11 & $0.60-2.03$ & & & 0.93 & $0.45-1.92$ & & \\
\hline 65-85 & 0.53 & $0.26-1.06$ & & & 0.48 & $0.22-1.05$ & & \\
\hline Gender & & & 2.95 & 0.086 & & & 0.52 & 0.471 \\
\hline Male & 1.00 & - & & & 1.00 & - & & \\
\hline Female & 1.26 & $0.96-1.64$ & & & 1.14 & $0.79-1.66$ & & \\
\hline Marital status & & & 1.61 & 0.447 & & & 0.43 & 0.807 \\
\hline Married/defacto & 1.00 & - & & & 1.00 & - & & \\
\hline Separated/widowed/divorced & 1.26 & $0.86-1.85$ & & & 1.13 & $0.77-1.67$ & & \\
\hline Never married & 1.17 & $0.79-1.72$ & & & 1.03 & $0.66-1.60$ & & \\
\hline Education & & & 1.07 & 0.586 & & & 5.62 & 0.060 \\
\hline Post-school education & 1.00 & - & & & 1.00 & - & & \\
\hline Completed high school & 1.26 & $0.86-1.85$ & & & 0.80 & $0.50-1.25$ & & \\
\hline Completed less than high school & 1.17 & $0.79-1.72$ & & & 1.42 & $0.95-2.12$ & & \\
\hline Employment status & & & 6.78 & 0.009 & & & 12.77 & $<0.001$ \\
\hline Currently employed & 0.69 & $0.51-0.92$ & & & 0.52 & $0.36-0.75$ & & \\
\hline Not in the labour force & 1.00 & - & & & 1.00 & - & & \\
\hline Country of birth & & & 0.11 & 0.738 & & & 1.10 & 0.293 \\
\hline Australia & 1.00 & - & & & 1.00 & - & & \\
\hline Other & 0.93 & $0.62-1.40$ & & & 1.34 & $0.77-2.34$ & & \\
\hline Socioeconomic status & & & 0.32 & 0.573 & & & 0.34 & 0.558 \\
\hline High & 1.00 & - & & & 1.00 & - & & \\
\hline Low & 1.08 & $0.82-1.43$ & & & 1.12 & $0.7-1.62$ & & \\
\hline Physical conditions & & & 48.03 & $<0.001$ & & & 32.99 & $<0.001$ \\
\hline One or more & 4.34 & $2.84-6.64$ & & & 4.67 & $2.73-7.98$ & & \\
\hline None & 1.00 & - & & & 1.00 & - & & \\
\hline Smoking status & & & 16.63 & $<0.001$ & & & 10.07 & 0.007 \\
\hline Current smoker & 1.90 & $1.39-2.61$ & & & 2.02 & $1.29-3.16$ & & \\
\hline Ex-smoker & 1.27 & $0.89-1.81$ & & & 1.43 & $1.01-2.01$ & & \\
\hline Never smoked & 1.00 & - & & & 1.00 & - & & \\
\hline Body mass index & & & 0.82 & 0.664 & & & 2.58 & 0.276 \\
\hline Underweight & 0.90 & $0.48-1.70$ & & & 0.71 & $0.20-2.54$ & & \\
\hline Normal weight & 1.00 & - & & & 1.00 & - & & \\
\hline Overweight/obese & 1.11 & $0.83-1.48$ & & & 1.26 & $0.91-1.75$ & & \\
\hline
\end{tabular}


disorders to be experienced with health anxiety. Additionally, respondents with a lifetime history of health anxiety were approximately six times more likely to experience at least one other physical or mental health condition at some point in their life in comparison with respondents without health anxiety. As demonstrated in Table 5, levels of non-specific psychological distress, functional impairment/activity limitation, disability days and mental health service use are all significantly elevated in respondents with health anxiety. Respondents with health anxiety had a mean K10 score of 22.67, a score that is consistent with high to severe levels of psychological distress. ${ }^{16,23}$ Indeed, respondents with health anxiety indicated that they were unable to work or conduct their normal activities for approximately 8 days in the previous 30 , which represents a fourfold increase when compared with the remainder of the population.

\section{Discussion}

\section{Main findings and comparison with findings from other studies}

The results of the current study provide an impression of how health anxiety affects the Australian general population. Approximately $6 \%$ of the population has experienced health anxiety at some point in their life and $3.4 \%$ had health anxiety at the time of the interview. The prevalence rate of health anxiety is non-trivial considering that this rate is similar to the lifetime prevalence of generalised anxiety disorder, panic disorder and
PTSD. ${ }^{12,24}$ There appears to be a significant trend across age, with the lowest prevalence observed in the young and old age groups, whereas the prevalence rate peaked in middle age. The peak of health anxiety in middle age could be explained by the onset of many chronic conditions at this time. This is further supported by a strong association between comorbid physical illness and health anxiety as evidenced by an odds ratio of 4.67. Consistent with a previous study by Bleichhardt \& Hiller, ${ }^{9}$ there were few other significant sociodemographic and health predictors, with only employment status, comorbid physical conditions and smoking status significantly predicting a diagnosis of health anxiety. One of the more compelling findings of the current study was that levels of comorbidity, distress, functional impairment, disability days and mental health service use were all significantly higher among respondents with health anxiety. This finding further confirms the conclusion drawn by Fink et al that health anxiety concerns must be taken seriously and diagnosed and treated as routine in order to reduce the unacceptable level of disease and economic burden.

The prevalence rate of health anxiety in this study is consistent with previous findings from population and primary practice samples (e.g. $7.7 \%$ in Noyes et $a^{25}$ ), but are higher than other estimates from population-based studies (e.g. $0.58 \%$ in Martin \& $\left.\mathrm{Jacobi}^{26}\right)$. The discrepancies in prevalence estimates across studies may have been influenced by various methodological differences, including interviewer type (lay $v$. clinically trained interviewers), assessment measures and differing definitions of

\begin{tabular}{|c|c|c|c|c|c|c|c|c|c|}
\hline \multirow[b]{2}{*}{ Disorder } & \multicolumn{4}{|c|}{ Lifetime health anxiety } & \multicolumn{5}{|c|}{ Current health anxiety } \\
\hline & $\begin{array}{l}\text { With } \\
\% \text { (s.e.) }\end{array}$ & $\begin{array}{l}\text { Without } \\
\% \text { (s.e.) }\end{array}$ & OR (95\% Cl) & $\begin{array}{c}\text { Wald } \\
F\end{array}$ & $\begin{array}{l}\text { With } \\
\% \text { (s.e.) }\end{array}$ & $\begin{array}{l}\text { Without } \\
\% \text { (s.e.) }\end{array}$ & OR $(95 \% \mathrm{Cl})$ & $\begin{array}{c}\text { Wald } \\
F\end{array}$ & $P$ \\
\hline Major depression & $37.4(3.42)$ & $11.4(0.48)$ & $4.66(3.42-6.34)$ & & $11.8(3.09)$ & $1.6(0.19)$ & $8.15(4.16-15.98)$ & & \\
\hline Dysthymia & $6.7(1.63)$ & $1.4(0.20)$ & $5.06(2.57-9.96)$ & & $5.4(2.45)$ & $0.5(0.11)$ & $10.87(3.03-38.98)$ & & \\
\hline Bipolar disorder & $9.1(1.39)$ & $0.9(0.17)$ & $11.38(6.75-19.20)$ & & $5.7(1.94)$ & $0.2(0.15)$ & $40.00(14.43-110.88)$ & & \\
\hline Any affective disorder & $46.8(3.60)$ & $12.4(0.47)$ & $6.20(4.59-8.37)$ & & 17.5 (3.74) & $1.9(0.20)$ & $11.12(6.11-20.22)$ & & \\
\hline Agoraphobia & $10.5(1.76)$ & $1.8(0.22)$ & $6.46(4.40-9.50)$ & & $5.2(1.10)$ & $0.4(0.08)$ & $13.38(6.73-26.60)$ & & \\
\hline Panic disorder & $12.2(2.30)$ & $3.0(0.27)$ & $4.45(2.80-7.07)$ & & $4.6(1.10)$ & $0.5(0.10)$ & $10.62(5.25-21.51)$ & & \\
\hline Social phobia & $29.1(2.48)$ & $7.1(0.38)$ & $5.35(4.13-6.93)$ & & $14.0(2.70)$ & $1.9(0.19)$ & $8.26(5.17-13.19)$ & & \\
\hline Generalised anxiety disorder & $23.8(2.77)$ & $5.0(0.38)$ & $5.89(4.12-8.44)$ & & $5.9(1.56)$ & $0.7(0.15)$ & $9.32(4.52-19.21)$ & & \\
\hline OCD & $11.4(2.01)$ & $3.3(0.26)$ & $3.77(2.45-5.80)$ & & $6.7(2.02)$ & $2.0(0.19)$ & $3.57(1.70-7.49)$ & & \\
\hline PTSD & $18.3(1.96)$ & $6.6(0.36)$ & $3.20(2.36-4.34)$ & & $13.3(2.46)$ & $2.1(0.22)$ & $7.25(4.38-12.01)$ & & \\
\hline Any anxiety disorder & $55.6(2.57)$ & $17.8(0.64)$ & $5.77(4.61-7.23)$ & & $31.8(3.21)$ & $5.9(0.35)$ & $7.37(5.32-10.21)$ & & \\
\hline Depression and anxiety & $68.4(2.60)$ & $23.3(0.70)$ & $7.12(5.57-9.11)$ & & $36.7(3.48)$ & $6.8(0.40)$ & $7.90(5.67-11.01)$ & & \\
\hline Any disorder & $80.0(2.06)$ & $40.2(0.86)$ & $5.94(4.58-7.70)$ & & - & - & - & & \\
\hline Mean number of disorders & $1.6(0.08)$ & $0.4(0.01)$ & & $471.01<0.001$ & $0.6(0.01)$ & $0.1(0.07)$ & & 215.02 & $<0.001$ \\
\hline
\end{tabular}

Table 5 Distress, impairment and service utilisation associated with and without current health anxiety in the Australian population

\begin{tabular}{|c|c|c|c|c|}
\hline & With current health anxiety & Without current health anxiety & Wald $F$ & $P$ \\
\hline Distress (K10), mean (s.e.) & $22.67(0.70)$ & $14.19(0.07)$ & 220.24 & $<0.001$ \\
\hline Impairment (WHODAS), mean (s.e.) & $25.86(1.99)$ & $8.74(0.55)$ & 114.05 & $<0.001$ \\
\hline Days out of role in previous 30 days, mean (s.e.) & $7.81(0.75)$ & $1.76(0.08)$ & 180.23 & $<0.001$ \\
\hline GP mental health consultations, ${ }^{\mathrm{a}} \%$ (s.e.) & $24.07(3.14)$ & $7.48(0.37)$ & 13.26 & $<0.001$ \\
\hline Specialist mental health consultations, ${ }^{a} \%$ (s.e.) & $23.23(3.59)$ & $5.76(0.37)$ & 22.5 & $<0.001$ \\
\hline
\end{tabular}


health anxiety. In the current study, health anxiety was defined as experiencing illness worries lasting for at least 6 months that persisted despite appropriate (self-reported) medical reassurance. This construct closely concords with broader definitions of health anxiety used in the literature (see Asmundson et $a l^{2}$ ). Commonly used terms include 'abridged form of hypochondriasis' 'subthreshold hypochondriasis' and 'illness worry' (see Gureje et $a l^{27}$ ), and are more prevalent than DSM-IV-defined hypochondriasis, which appears relatively rare and difficult to diagnose due to strict inclusion criteria. ${ }^{27-29}$

Indeed, the broader definition of health anxiety used in this study potentially identified individuals with DSM-IV-defined hypochondriasis as well as individuals with subthreshold or less severe health anxiety who may fail to meet all the criteria yet remain significantly distressed and impaired. Kessler et al ${ }^{30}$ defended the recognition and diagnosis of mild or subthreshold mental disorders stating that they can be early signs of psychopathology that further develop into severe disorders with multiple comorbidities. However, at this stage there is no conclusive evidence suggesting that subthreshold cases of health anxiety progress further to the more severe concept of hypochondriasis. The current study provides evidence of the validity of the broader health anxiety diagnostic construct since those who experienced health anxiety were significantly more distressed and impaired in comparison with those who did not meet criteria and therefore may benefit from treatment. Indeed, the mean level of psychological distress identified in respondents with health anxiety was consistent with previous mean K10 scores found in respondents with a DSM-IV diagnosis of affective and anxiety disorders. ${ }^{31}$ Individuals with health anxiety reported significantly more days out of role due to disability, totalling approximately 8 in the past 30 days, which denotes significant disability and loss of quality of life. This important finding was identified previously by Bleichhardt \& Hiller, ${ }^{9}$ who concluded that severe health anxiety (observed in $6 \%$ of their sample) considerably reduced healthrelated quality of life and increased health service utilisation. These findings suggest that further research is required to examine the validity of this construct and determine whether classification and recognition of hypochondriasis or severe health anxiety can be improved for the upcoming revision of the DSM.

Those with current health anxiety were shown to utilise mental health services at a significantly higher rate than those without health anxiety, as approximately a quarter of individuals with health anxiety reported seeing a GP in the past 12 months for a mental health problem. This finding indicates that many people with health anxiety are more likely to seek help and treatment for their disorder or a related condition. Unfortunately, this result also indicates that the same proportion of individuals with current health anxiety have failed to receive effective treatment or satisfactory professional help and therefore may remain in various health services for a long time without significant improvement. Conradt et $a l^{32}$ (p. 137) wrote the disorder has a major impact on interpersonal relationships, in general, and on the doctor-patient relationship in particular... resulting in consultations that are experienced by both doctor and patient as frustrating and unsatisfactory'. The current study was not able to examine the effectiveness of treatments received by respondents with health anxiety nor was it able to examine the number and length of time spent in various health services. In addition, it is hypothesised that many respondents with health anxiety will seek treatment pertaining to a physical rather than a mental condition but the specific detail regarding physical consultations was not available and hence the current results perhaps represent an underrepresentation of total health service utilisation. Future research must examine these issues if any significant improvements in treatment and prevention of health anxiety are to be made.

\section{Limitations}

The interpretation of the findings should be made while considering some limitations of the current study. Despite examining a representative sample of the Australian population, the current study analysed retrospective self-report to estimate the prevalence of lifetime health anxiety. Previous studies have demonstrated that recall bias can significantly influence the prevalence estimates generated from retrospective designs and therefore caution must be taken when interpreting the current results. ${ }^{33,34}$ However, data from longitudinal prospective studies on health anxiety, which are theoretically free from recall bias and could provide some indication of over- or underestimation of prevalence, are currently unavailable. Further research is required to investigate the influence of self-report and recall bias on the prevalence estimates reported in the current study.

A secondary caveat of the current study was that the diagnostic status of health anxiety was evaluated utilising brief screening questions rather than systematically addressing each diagnostic criterion required by the DSM-IV, therefore precluding the ability to strictly examine DSM-IV-defined hypochondriasis. The screening questions did not allow for an assessment of whether differential diagnoses (such as generalised anxiety disorder) better accounted for participants' illness concerns (Criterion C and Criterion F in the DSM-IV). Therefore, the prevalence rates found in this study may reflect in part 'true' primary DSM-IV Axis I diagnoses of hypochondriasis, as well as hypochondriacal concerns that are better accounted for by other Axis I disorders. Regardless of whether the illness concerns are attributed to a primary disorder of hypochondriasis, subthreshold hypochondriasis or secondary to other Axis I disorders, our results indicate that these symptoms are prevalent, debilitating and associated with high mental health service use, indicating the need for treatment and recognition of this condition.

Third, the assessment of DSM-IV Criterion B for hypochondriasis, illness worries persisting despite appropriate medical reassurance, was based solely on participants' subjective and retrospective self-report, and not validated by a health professional. This may have potentially overinflated the prevalence estimate of health anxiety by encouraging positive responses, suggesting the estimates should be interpreted with caution.

\section{Implications}

The current study represents the first population-based epidemiological data for health anxiety in the Australian population. The main findings of the study suggest that the prevalence of health anxiety is non-trivial, there are few sociodemographic predictors and only comorbid conditions and current smoking status are significant health predictors of health anxiety. Individuals with health anxiety are at higher risk for many comorbid anxiety and affective disorders and they exhibit significantly more distress, functional impairment, disability and mental health service utilisation. In short, health anxiety is a disabling condition and requires further research and clinical attention.

Matthew Sunderland, PhD, Jill M. Newby, PhD, Gavin Andrews, MD, Clinical Research Unit for anxiety and depression, School of Psychiatry, University of New South Wales at St Vincent's Hospital, Darlinghurst, Australia

Correspondence: Matthew Sunderland, Level 4, O'Brien Centre, St Vincent's Hospital, 394-404 Victoria Street, Darlinghurst, NSW 2010, Australia. Email: matthews@unsw.edu.au

First received 29 Sep 2011, final revision 4 Jan 2012, accepted 31 Jan 2012 


\section{Appendix}

\section{Assessment items}

1 Have you ever worried a lot about serious illness despite reassurance from a doctor?

2 Has a period of worry like this ever continued for 6 months or more?

3 Did a period of worry like this include any of the time in the last 12 months?

4 Is this worry still going on?

\section{References}

1 American Psychiatric Association. Diagnostic and Statistical Manual of Mental Disorders (4th edn) (DSM-IV). APA, 1994.

2 Asmundson GJ, Abramowitz JS, Richter AA, Whedon M. Health anxiety: current perspectives and future directions. Curr Psychiatry Rep 2010; 12 306-12.

3 Barsky AJ, Fama JM, Bailey ED, Ahern DK. A prospective 4- to 5-year study of DSM-III-R hypochondriasis. Arch Gen Psychiatry 1998; 55: 737-44.

4 Barsky AJ, Ettner SL, Horsky J, Bates DW. Resource utilization of patients with hypochondriacal health anxiety and somatization. Med Care 2001; 39 705-15.

5 Barsky AJ, Wyshak G, Klerman GL. Hypochondriasis: an evaluation of the DSM-III criteria in medical outpatients. Arch Gen Psychiatry 1986; 43 493-500.

6 Fink $\mathrm{P}$, Ornbol $\mathrm{E}$, Sparle $\mathrm{C}$. The outcome of health anxiety in primary care. A two-year follow-up study on health care costs and self-rated health. PLOS One 2010; 5: e9873.

7 Katon WJ, Walker EA. Medically unexplained symptoms in primary care. J Clin Psychiatry 1998; 59: 15-21.

8 Mykletun A, Heradstveit O, Eriksen K, Glozier N, Overland S, Maeland JG et al. Health anxiety and disability pension award: the HUSK study. Psychosom Med 2009; 71: 353-60.

9 Bleichhardt G, Hiller W. Hypochondriasis and health anxiety in the German population. Br J Health Psychol 2007; 12: 511-23.

10 Andrews G, Issakidis C, Sanderson K, Corry J, Lapsley H. Utilising survey data to inform public policy: comparison of the cost-effectiveness of treatment of ten mental disorders. Br J Psychiatry 2004; 184: 526-33.

11 Jenkins R. Making psychiatric epidemiology useful: the contribution of epidemiology to government policy. Acta Psychiatr Scand 2001; 103: 2-14.

12 Slade T, Johnston A, Oakley-Browne MA, Andrews G, Whiteford H. 2007 National Survey of Mental Health and Wellbeing: methods and key findings. Aust N Z J Psychiatry 2009; 43: 594-605.

13 Kessler RC, Ustün TB. The World Mental Health Survey Initiative version of the World Health Organization Composite International Diagnostic Interview. Int J Methods Psychiatr Res 2004; 13: 93-121.

14 Kessler RC, Abelson J, Demler O, Escobar Jl, Gibbon M, Guyer ME, et al. Clinical calibration of DSM-IV diagnoses in the World Mental Health version of the World Health Organization Composite International Diagnostic Interview. Int J Methods Psychiatr Res 2004; 13: 122-39.
15 Kessler RC, Andrews G, Colpe U, Hiripi E, Mroczek DK, Normand SLT, et al. Short screening scales to monitor population prevalences and trends in non-specific psychological distress. Psychol Med 2002; 32: 959-76.

16 Andrews G, Slade T. Interpreting scores on the Kessler Psychological Distress Scale (K10). Aust N Z J Public Health 2001; 26: 494-7.

17 Furukawa TA, Kessler RC, Slade T, Andrews G. The performance of the K6 and $\mathrm{K} 10$ screening scales for psychological distress in the Australian National Survey of Mental Health and Well-being. Psychol Med 2003; 33: 357-62.

18 Kessler RC, Green JG, Gruber MJ, Sampson NA, Bromet E, Cuitan M, et al. Screening for serious mental illness in the general population with the K6 screening scale: results from the WHO World Mental Health (WMH) survey initiative. Int J Methods Psychiatr Res 2010; 19: 4-22.

19 Sunderland M, Slade T, Stewart G, Andrews G. Estimating the prevalence of DSM-IV mental illness in the Australian general population using the Kessler Psychological Distress scale. Aust N Z J Psychiatry 2011; 45: 880-9.

20 Andrews G, Kemp A, Sunderland M, Von Korff M, Ustun TB. Normative data for the 12 item WHO Disability Assessment Schedule 2.0. PLOS One 2009; 4: e8343.

21 Wolter KM. Introduction to Variance Estimation. Springer Science, 2007.

22 Shah BV, Barnwell BG, Biegler GS. SUDAAN User's Manual. Research Triangle Park, 1997.

23 Australian Bureau of Statistics. Information Paper: Use of the Kessler Psychological Distress Scale in ABS Health Surveys, Australia. Australian Bureau of Statistics, 2001.

24 Kessler RC, Berglund P, Demler O, Jin R, Merikangas KR, Walters EE. Prevalence, severity, and comorbidity of 12-month DSM-IV disorders in the National Comorbidity Survey Replication. Arch Gen Psychiatry 2005; 62 593-602.

25 Noyes R, Happel RL, Yagla SJ. Correlates of hypochondriasis in a nonclinical population. Psychosomatics 1999; 40: 461-9.

26 Martin A, Jacobi F. Features of hypochondriasis and illness worry in the general population in Germany. Psychosom Med 2006; 68: 770-7.

27 Gureje O, Ustun TB, Simon GE. The syndrome of health anxiety: a crossnational study in primary care. Psychol Med 1997; 27: 1000-10.

28 Creed F, Barsky A. A systematic review of the epidemiology of somatisation disorder and hypochondriasis. J Psychosom Res 2004; 56: 391-408.

29 Escobar Jl, Gara M, Waitzkin H, Silver RC, Holman A, Compton W. DSM-IV hypochondriasis in primary care. Gen Hosp Psychiatry 1998; 20: 155-9.

30 Kessler RC, Merikangas KR, Berglund P, Eaton WW, Koretz DS, Walters EE. Mild disorders should not be eliminated from the DSM-V. Arch Gen Psychiatry 2003; 60: 1117-22.

31 Slade T, Grove R, Burgess P. Kessler Psychological Distress Scale: normative data from the 2007 Australian National Survey of Mental Health and Wellbeing. Aust N Z J Psychiatry 2011; 45: 308-16.

32 Conradt M, Cavanagh M, Franklin J, Rief W. Dimensionality of the Whitely index: assessment of hypochondriasis in an Australian sample of primary care patients. J Psychosom Res 2006; 60: 137-43.

33 Streiner DL, Patten SB, Anthony JC, Cairney J. Has 'lifetime prevalence' reached the end of its life? An examination of the concept. Int J Methods Psychiatr Res 2009; 18: 221-8.

34 Patten SB. Accumulation of major depressive episodes over time in a prospective study indicates that retrospectively assessed lifetime prevalence estimates are too low. BMC Psychiatry 2009; 9: 19. 